\title{
EFFECT OF ULTRASONICATION ON MICROBIAL QUALITY, COLOUR, AND ASCORBIC ACID CONTENT OF PASSION-FRUIT JUICE DURING STORAGE
}

\author{
V.M. Gómez-López ${ }^{a *}$, M.E. Buitrago ${ }^{b}$, M.S. TAPia ${ }^{b}$ and A. Martínez-Yépez ${ }^{b}$ \\ ${ }^{a}$ Cátedra Alimentos para la Salud, Universidad Católica de Murcia (UCAM), Campus de los Jerónimos 135, \\ Guadalupe 30107, Murcia. Spain \\ bInstituto de Ciencia y Tecnología de Alimentos, Facultad de Ciencias, Universidad Central de Venezuela. \\ Apartado 47097, Caracas 1041A. Venezuela.
}

(Received: 23 January 2017; accepted: 24 April 2017)

\begin{abstract}
Passion fruit juice (PFJ) has a delicate flavour, very susceptible to thermal degradation. This study pursued to test the effect of sonication as non-thermal preservation method on some quality parameters of PFJ. The effect of ultrasound $(20 \mathrm{kHz}, 263 \mathrm{~W}, 89.25 \mu \mathrm{m})$ on the indigenous microflora, colour, $\mathrm{pH}$, and ascorbic acid content of PFJ was studied. Firstly, the kinetic of microbial inactivation was determined for aerobic mesophilic bacteria and yeasts. Data was fitted to Weibull model, and a treatment time of 8 min was selected for stability studies. To this, untreated and sonicated juice was stored at 4 and $10{ }^{\circ} \mathrm{C}$ up to 10 days and microbial quality, instrumental colour, $\mathrm{pH}$, and ascorbic acid content were evaluated. In general, ultrasound kept juice microbiologically stable for up to 10 days at $4{ }^{\circ} \mathrm{C}$ without markedly affecting other parameters evaluated. Ultrasound seems suitable to stabilize PFJ microbiologically.
\end{abstract}

Keywords: ultrasound processing, fruit juices, microbial inactivation, preservation

High power ultrasound refers to pressure waves with a frequency of $20 \mathrm{KHz}$ or more, and it has the ability to cause cavitation, which inactivates microorganisms. Cavitation micro bubbles are generated by pressure changes that collapse violently in the succeeding compression cycles of a propagated sonic wave, resulting in regions of high localized temperature and high shearing effects. The intense local energy and high pressure bring about a localized sterilization effect (PIYASENA et al., 2003). Sonication is considered a suitable technique for treatment of liquid foods due to the fact that transferring of acoustic energy to food is instantaneous and throughout the whole product, with reduction of the processing time, higher throughput, and lower energy consumption (CHENG et al., 2007). As a consequence, it has been investigated as a way to provide high quality fruit juices. Sonication may affect key quality parameters, such as colour and ascorbic acid content, however such effects are generally subtle (TIWARI et al., 2008a). The use of sonication in fruit juice processing is a topic of current interest; recent research has been conducted on juices of pomegranate (Uysal et al., 2015), blueberry (MohideEn et al., 2015), and orange (Guerrouj et al., 2016) among others.

There is a growing demand for processed fruit pulp with particular interest to tropical fruit juice production, since the consumption of tropical or "exotic" fruit has increased all over the world (FRESHFEL, 2015), arousing industry interest to search for novel technologies.

\footnotetext{
* To whom correspondence should be addressed. Phone: +34968278 638; e-mail: vmgomez@ucam.edu
} 
Passion fruit is one of the most exotic fruits. Its juice has a delicate flavour that is very susceptible to thermal degradation. Pasteurization of passion fruit juice (PFJ) at $75{ }^{\circ} \mathrm{C}$ for 60 sec drastically reduces the concentration of its four key volatiles (SANDI et al., 2004). Additionally, thermal processing of passion fruit results in the production of the toxic compound 5-hydroxymethyl-2-furfural (SOARES et al., 2017) and the degradation of some bioactive compounds; for example, $15 \%$ loss of ascorbic acid and $12 \%$ loss of carotenoids have been reported for PFJ subjected to pasteurization at $90{ }^{\circ} \mathrm{C}$ for $60 \mathrm{sec}$ (FERnANDES et al., 2011). For these reasons, non-thermal processing may be required to produce high quality stable PFJ. To the best of our knowledge, sonication of PFJ has not yet been documented.

Furthermore, there is a trend nowadays to supplement fruit juices with minerals, which is most prominent in the orange juice industry (BERK, 2016). The addition of calcium to exotic fruit juices such as PFJ gives them an additional attractive feature on the market as well as contributes to consumer's health.

The goal of this study was to evaluate the effects of sonication on the stability of PFJ by determining the changes in microbial populations, instrumental color, $\mathrm{pH}$, and ascorbic acid content during storage at two low temperatures.

\section{Materials and methods}

\subsection{Preparation of PFJ samples}

Yellow passion fruits (Passiflora edulis f. flavicarpa Degener) were purchased in a local market (Caracas, Venezuela). Unblemished fruit were selected, washed, and subjected to an extraction process using a commercial juice extractor (Omega Products, Inc., Harrisburg, PA). The fresh juice was standardized with commercial sucrose to a total soluble solids/total titratable acidity ratio of 5 , and $425 \mathrm{mg}$ of calcium (Gynopharm, Venezuela) per $100 \mathrm{ml}$ of juice was added in order to enhance the nutrient content of the juice. Total soluble solids were determined with a manual refractometer (Atago PR-101, Tokyo, Japan) and expressed in Brix degrees corrected to $25^{\circ} \mathrm{C}$ (method 932.12 , AOAC, 1990), and total titratable acidity by titration with $\mathrm{NaOH}$ (method $942.15 \mathrm{~B}, \mathrm{AOAC}, 1990$ ) and expressed as citric acid percent.

\subsection{Ultrasound treatment}

PFJ was treated by ultrasonication in two kinds of experiments. In the first, the inactivation of relevant microbial groups was studied for 10 minutes of sonication by withdrawing juice samples every two minutes. The sonication parameters, by which a significant $(\mathrm{P}<0.05)$ microbial inactivation was achieved, were selected based on our previous study (GómEZLópez et al., 2010). In the second experiment, PFJ was treated under conditions selected according to the results of the first experiment, and then stored for stability studies.

Ultrasonic treatment was carried out in a refrigerated cylindrical vessel that kept juice temperature at $10{ }^{\circ} \mathrm{C}$. Ultrasound at a frequency of $20 \mathrm{kHz}$ was applied continuously to 100 $\mathrm{ml}$ of PFJ using an ultrasonic unit with a rated power of $500 \mathrm{~W}$ (CPX-500, Cole-Parmer, Chicago, IL) and a $13 \mathrm{~mm}$ diameter probe with a tip kept $4 \mathrm{~cm}$ from the vessel's bottom. Treatment time was the only parameter that was changed during the tests; which was extended up to $10 \mathrm{~min}$, since this duration proved to be enough to stabilize other fruit juices treated under similar conditions (Gómez-López et al., 2010). The juice was sonicated at 75\% power (89.25 $\mu \mathrm{m}$ wave amplitude), which is the maximum power that can be set for the probe 
without risking its fracture according to the manufacturer's instructions. Supposing a mean transducer efficiency of $70 \%(\mathrm{y})$, the acoustic power (WA) actually supplied into the juice was $263 \mathrm{~W}$ according to the equation of BEVILACQUA and co-workers (2014).

\subsection{Microbial analysis}

Aerobic mesophilic count (AMC) and yeast and mould count were determined for kinetic modelling as well as for stability studies during storage. Samples were aseptically taken at the set time intervals, and serially diluted in $0.1 \mathrm{mg} / 100 \mathrm{~g}$ peptone water. AMC was determined by pour plating with PCA (Merck, Darmstadt, Germany), overlaid with the same medium, and incubation at $35-37^{\circ} \mathrm{C}$ for $1-2$ days. Yeast and mould counts were determined by spread plating on acidified PDA (Merck) and incubation at $20-25^{\circ} \mathrm{C}$ for $3-5$ days. Results are means of triplicates.

\subsection{Stability of the sonicated juice}

Untreated (control) and PFJ sonicated for 8 min were aseptically packed in sterile screwedcapped glass bottles and stored at 4 and $10{ }^{\circ} \mathrm{C}$, for 10 days. Samples were taken at set time intervals $(0,2,4,6,8$, and 10 days), and different quality indicators were evaluated, namely: AMC, yeast and mould counts, instrumental colour, $\mathrm{pH}$, and ascorbic acid concentration. All measurements were made in triplicate. Microbial quality was assessed as described before and other parameters as stated next.

1.4.1. Instrumental colour measurement. Instrumental colour was determined in triplicate using the Hunter Lab space system by means of a Macbeth ${ }^{\circledR}$ colour-eye colorimeter Model 2445 (New Windsor, NY) with a CIE Standard Illuminant D65 and a CIE $19312^{\circ}$ Standard Observer; the colorimeter was calibrated with a white standard tile $(\mathrm{L}=94.61, \mathrm{a}=$ -1.17 , and $b=2.17)$.

1.4.2. $\mathrm{pH}$ determination. $\mathrm{pH}$ was measured by method 945.10 (AOAC, 1990) with a $\mathrm{pH}$ meter HI 9321 (Hanna Instruments, Padova, Italy).

1.4.3. Ascorbic acid concentration. Ascorbic acid was determined by the microfluorometric method 967.22 of AOAC (1990) and fluorescence measured by a spectrofluorophotometer RF-530 IPC (Shimadzu Corporation, Kyoto, Japan).

\subsection{Data analysis}

Inactivation curves were fitted to eight models by using GInaFiT (GEeraerd et al., 2005); only the results for Weibull and log-linear + shoulder models are shown, because they yielded the best fit (lowest root mean squared error, RMSE).

The Weibull model reads as follows:

$$
\log N=\log N_{o}-\left(\frac{t}{\delta}\right)^{p}
$$

Herein, $N$ stands for the number of surviving microorganisms, $N_{0}$ for the initial number of microorganisms, $t$ is the treatment time, $\delta$ (time unit) is a scale parameter, and $p$ (dimensionless) a shape parameter. 
The log-linear + shoulder model reads as follows:

$$
\log N=\log N_{0} \cdot e^{-k_{\max } \cdot t} \cdot\left(\frac{e^{k_{\max } \cdot S_{l}}}{1+\left(e^{k_{\max } \cdot S_{l}}-1\right) \cdot e^{-k_{\max } \cdot t}}\right)
$$

Herein, $k_{\max }$ (units: inverse of time) stands for the first order inactivation constant and $S_{1}$ (time units) for the shoulder length (GEERAERD et al., 2005).

Statistical analysis was carried out by firstly checking normality by the KolmogorovSmirnov test and homoscedasticity by the Levene's test. Parametric comparisons were performed by using ANOVA and Tukey tests at $\mathrm{P}=0.05$ in all cases except for the inactivation curve for yeasts. In this case, the Kruskal-Wallis test was used for media comparisons, since data did not fulfil homoscedasticity. Statistical analysis was carried out using IBM SPSS Statistics 24 (IBM, Armonk, USA). $\mathrm{P}=0.05$ was used in all cases.

\section{Results and discussion}

\subsection{Microbial inactivation}

Ultrasound treatment was able to decrease the aerobic mesophilic count (AMC) and yeast count (YC) of PFJ; no moulds were detected. The inactivation curves are shown in Figure 1A for AMC and Fig. 1B for YC, and results of modelling parameters are shown in Table 1. Weibull and log-linear + shoulder models gave identical curves, only curves corresponding to the Weibull model are shown in Figure 1, following the parsimony principle. The Weibull model has been widely used to describe the kinetic of microbial inactivation in fruit juices by ultrasonication, such as natural microflora in orange juice (GómEZ-LóPEZ et al., 2010) and Saccharomyces cerevisiae in pomegranate juice (Uysal et al., 2015).

Table 1. Parameters of the Weibull and log-linear + shoulder models for mesophilic aerobic counts and yeast counts $\left(\log \mathrm{CFU} \mathrm{ml} l^{-1}\right)$ of sonicated passion fruit juice

\begin{tabular}{lccccc}
\hline \multirow{2}{*}{ Parameters } & \multicolumn{2}{c}{ Mesophilic aerobic counts } & & \multicolumn{2}{c}{ Yeast counts } \\
\cline { 2 - 3 } \cline { 5 - 6 } & $\begin{array}{c}\text { Log-linear }+ \\
\text { shoulder }\end{array}$ & Weibull & & $\begin{array}{c}\text { Log-linear }+ \\
\text { shoulder }\end{array}$ & Weibull \\
\hline RMSE & 0.0458 & 0.0464 & & 0.0892 & 0.0895 \\
$\mathrm{R}^{2}$ & 0.9830 & 0.9826 & & 0.9763 & 0.9761 \\
$\delta(\min )$ & & $11.66 \pm 0.49$ & & $8.94 \pm 0.68$ \\
$\mathrm{p}($ dimensionless $)$ & $5.17 \pm 0.03$ & $5.16 \pm 0.03$ & & $5.08 \pm 0.08$ & $1.33 \pm 0.29$ \\
Log $\left(\mathrm{N}_{\mathrm{o}}\right)$ & $7.02 \pm 0.58$ & & $2.84 \pm 0.46$ & & $5.07 \pm 0.08$ \\
$\mathrm{~S}_{1}(\min )$ & $0.47 \pm 0.08$ & & $0.37 \pm 0.08$ & \\
$\mathrm{k}_{\max }\left(\min ^{-1}\right)$ & & & & \\
\hline
\end{tabular}

RMSE: Root mean squared error; $\delta$ : time for the first decimal reduction; $p$ : parameter describing concavity or convexity of the curve; $\mathrm{S}_{1}$ : shoulder length; $\mathrm{k}_{\max }$ : specific inactivation rate 

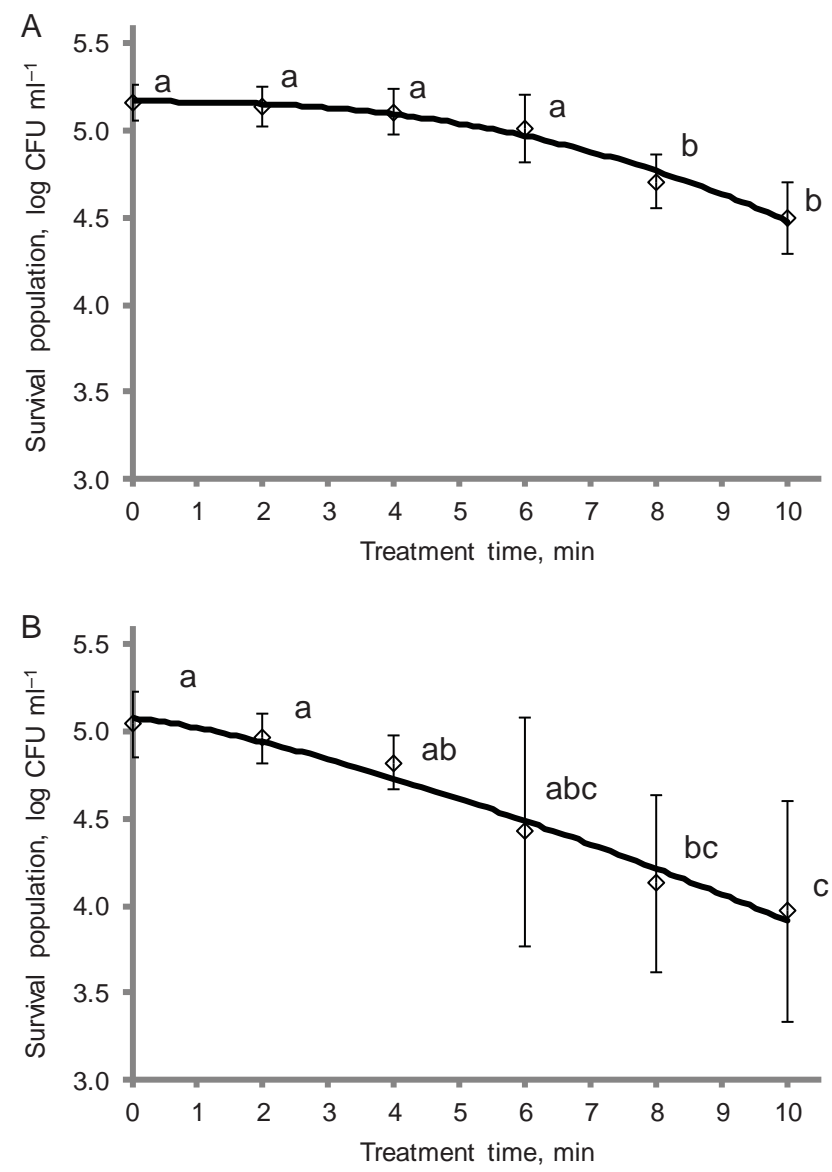

Fig. 1. Microbial inactivation of aerobic mesophilic counts (A) and yeast counts (B) of sonicated passion fruit juice. Curves are fitted to Weibull model. ${ }^{\text {abc }}$ : Points with different letters are statistically different $(\mathrm{P}<0.05)$

Figure 1 shows that both microbial groups exhibited a shoulder followed by an inactivation phase, which means that the damage caused by the ultrasound treatment to both microbial groups is not enough to start their immediate inactivation, but a threshold must be reached to start decreasing their viability. The shoulder length was longer for AMC than for $\mathrm{YC}$, as it can be observed in Figure 1 and has been quantified in Table 1, which means that more energy is required to start the inactivation of bactera than for yeasts. The inactivation phase of both curves exhibited downward concavity, as it can be observed in Figure 1, and a $\mathrm{p}$ value (shape value) $>1$ (Table 1 ) in the Weibull model, which was more pronounced for AMC inactivation. Values for the other parameters of the inactivation phase, $\delta$ and $\mathrm{K}_{\max }$ are in line with previous reports (GómEz-LóPEZ et al., 2010; UysAL et al., 2015). The lowest microbial counts in the current study were found for the $10 \mathrm{~min}$ treatment. However, a shorter time ( $8 \mathrm{~min}$ ) was selected for storage studies, since counts after $8 \mathrm{~min}$ of sonication were statistically equal to those at $10 \mathrm{~min}(\mathrm{P}>0.05)$. 


\subsection{Microbiological stability}

The evolution of microbial populations during storage at cold temperatures is shown in Figure 2. It can be observed at day 0 that sonication decreased AMC by $1.35 \log \mathrm{CFU} \mathrm{ml}{ }^{-1}$ (Fig. 2A), and YC by $0.74 \log \mathrm{CFU} \mathrm{ml}^{-1}$ (Fig. 2B). The results are in line with other values reported for indigenous microflora of different fruit juices, such as those made from orange (VAlero et al., 2007; GómEz-López et al., 2010) and blueberry (Mohideen et al., 2015), which are not higher than $2 \log \mathrm{CFU} \mathrm{ml} l^{-1}$.
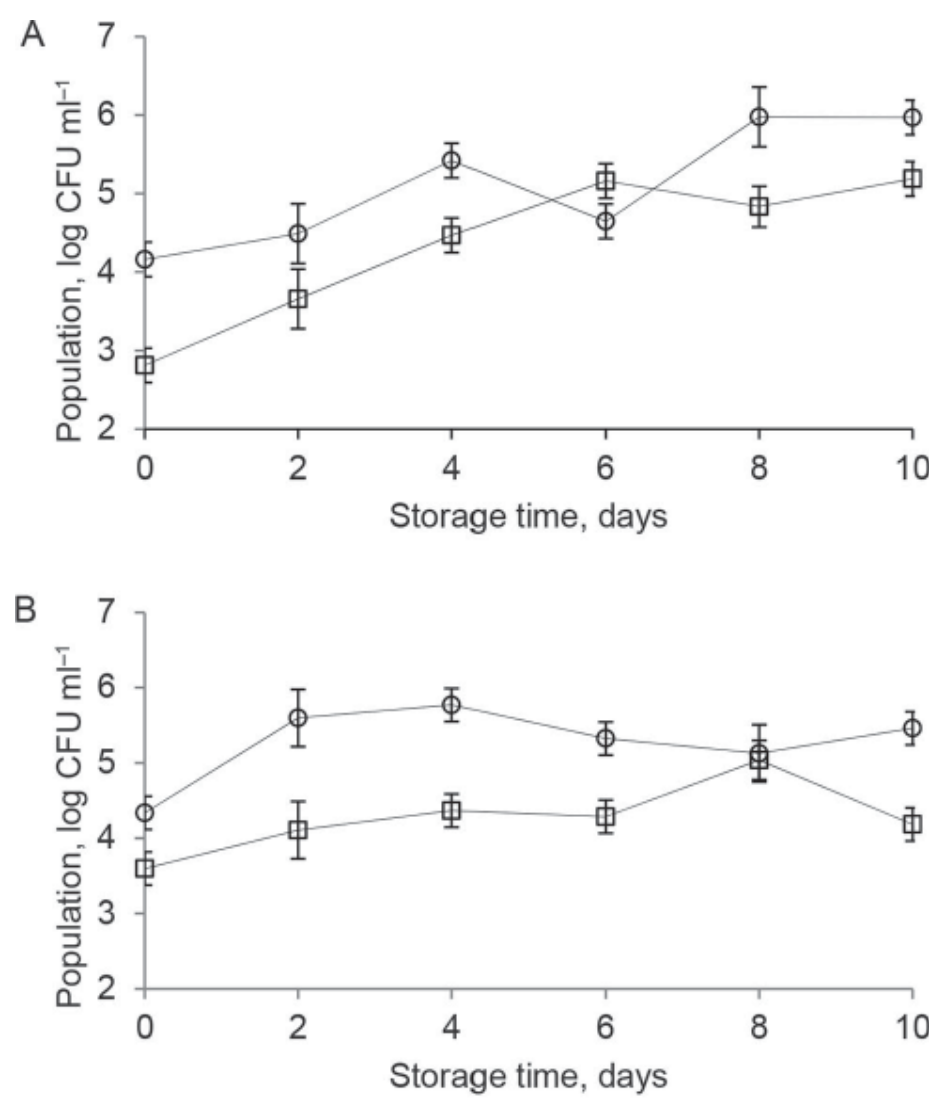

Fig. 2. Microbial stability of untreated and sonicated passion fruit juice stored at two different temperatures. Aerobic mesophilic counts (A) and yeast counts (B) at $4{ }^{\circ} \mathrm{C}$; aerobic mesophilic counts (C) and yeast counts (D) at $10{ }^{\circ} \mathrm{C}$. o: untreated; $\square$ : sonicated 

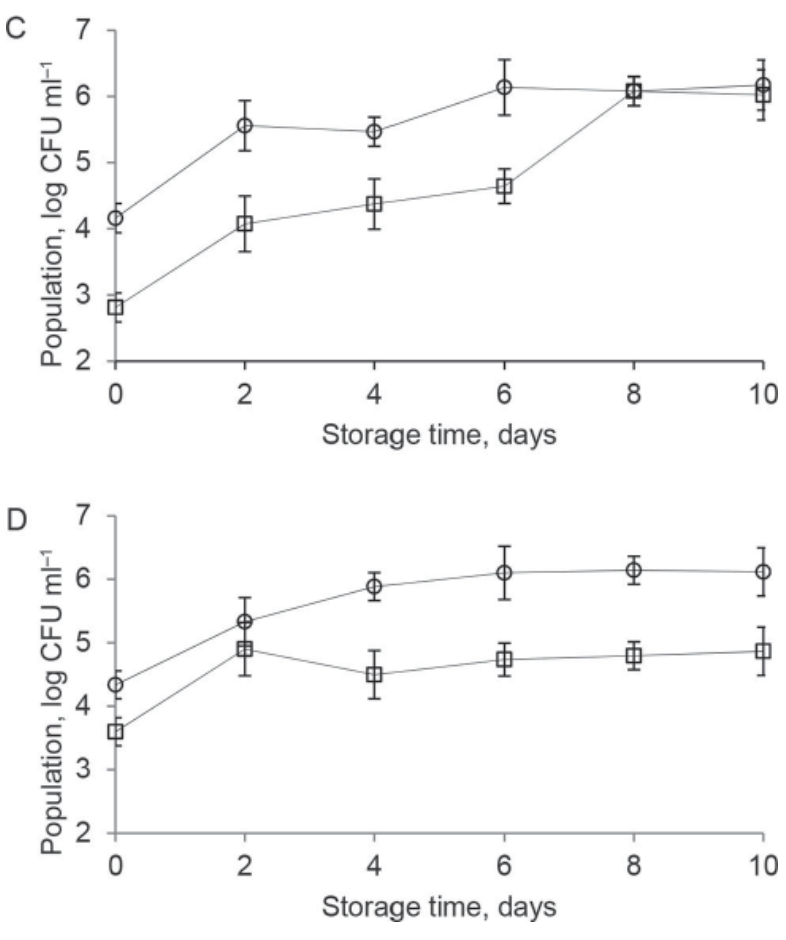

Fig. 2. continued

Overall, microbial populations of sonicated samples were persistently lower than those of non-sonicated samples during refrigerated storage. That occurred specifically at $4{ }^{\circ} \mathrm{C}$, where microbial counts after 10 days of storage were similar to those initially achieved by the ultrasound treatment, as it has also reported for ultrasound-treated orange juice stored at $4{ }^{\circ} \mathrm{C}$ (Gómez-López et al., 2010) and $5{ }^{\circ} \mathrm{C}$ (Guerrouj et al., 2016). This indicates that sonication brought about a PFJ with higher microbiological quality than untreated juice up to 10 days. At $10^{\circ} \mathrm{C}$, however, the stability did not last beyond the sixth day due to increase in AMC (Fig. 2C) in spite of the stability of YC (Fig. 2D).

\subsection{Colour}

PFJ has a characteristic intense yellow colour. Ultrasound altered its colour parameters, which were determined instrumentally $(\mathrm{P}<0.05)$. The juice became lighter, greener, and yellower (Fig. 3). Changes were small (from 31.68 to 32.92 for lightness, from -0.81 to -1.30 for "a", and from 35.70 to 37.15 for "b") and their magnitude comparable with results reported by VALERO and co-workers (2007) and TIWARI and co-workers (2008b) for sonicated orange juice. After the initial changes caused by the treatment, the colour was stable during storage, with changes between day 0 and 10 that did not exceed $-1.4,0.3$, and 2.1 for $\mathrm{L}$, a, and $b$ parameters, respectively. As a consequence, the differences between sonicated and control samples persisted during the 10-day shelf-life experiment, with no considerable effect of storage temperature. The increase in lightness of PFJ after sonication could be a result of 
decreasing particle size (VALERO et al., 2007), and the further stability of this parameter during storage could be related to the decrease in ascorbic acid concentration (Fig. 4), since the oxidation of this compound has been related to lightness reduction after thermal processing of PFJ (SANDI et al., 2004). Carotenes are major pigments present in yellow fruit juices, and changes in colour parameters a and $\mathrm{b}$ might be related to carotenoid isomerization (SANDI et al., 2004).

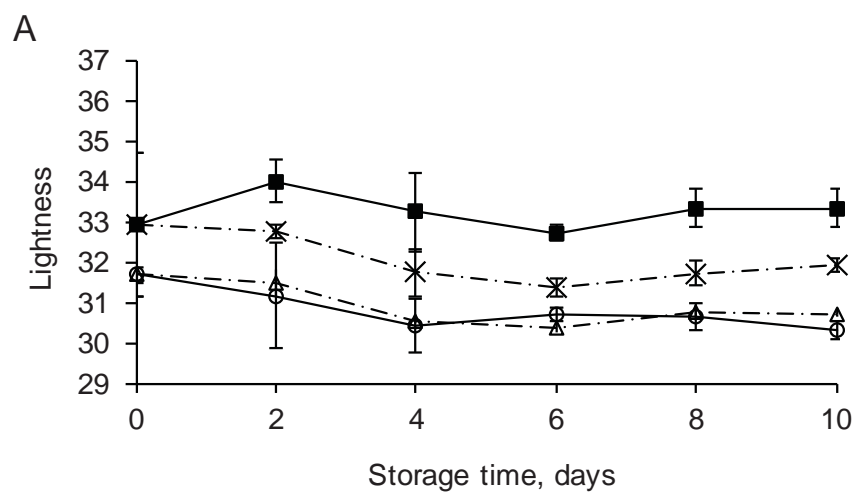

B Storage time, days
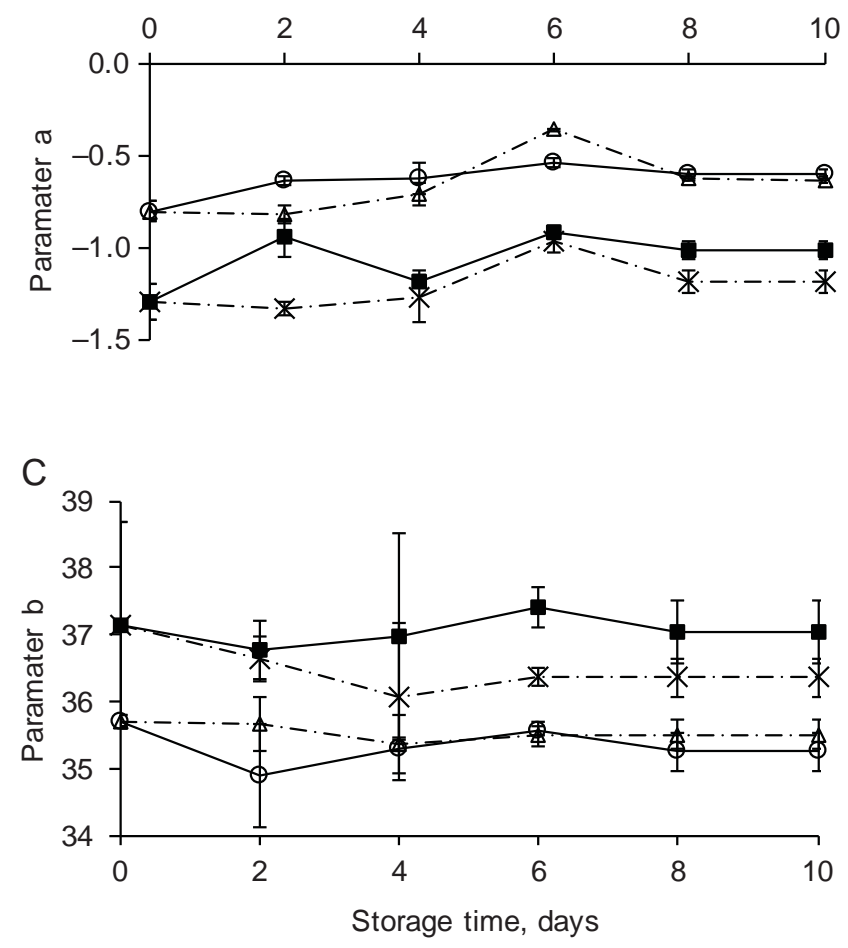

Fig. 3. Colour of untreated and sonicated passion fruit juice stored at 4 and $10^{\circ} \mathrm{C}$. Lightness (A), parameter " $a$ " (B), parameter " $b$ " (C). o: control, $4{ }^{\circ} \mathrm{C}$; m: sonicated, $4{ }^{\circ} \mathrm{C} ; \Delta$ : control, $10^{\circ} \mathrm{C}$; x: sonicated, $10^{\circ} \mathrm{C}$ 


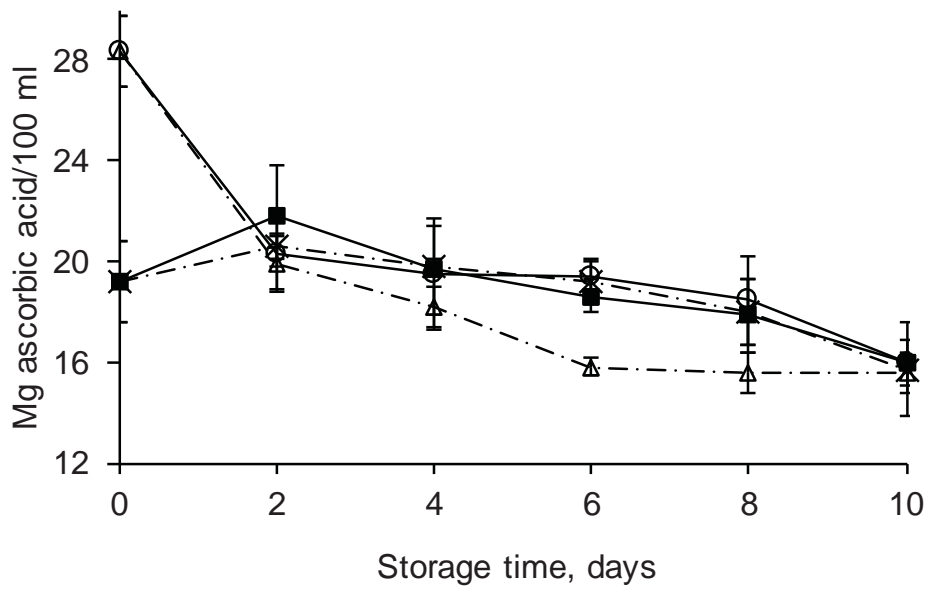

Fig. 4. Changes in ascorbic acid content during storage of untreated and sonicated passion fruit juice. o: control, 4 ${ }^{\circ} \mathrm{C}$; : sonicated, $4{ }^{\circ} \mathrm{C} ; \Delta$ : control, $10{ }^{\circ} \mathrm{C}$; $\mathrm{x}$ : sonicated, $10{ }^{\circ} \mathrm{C}$

\section{4. $p H$}

The $\mathrm{pH}$ was in the range of 2.98-3.10 (Table 2) and showed statistically different values $(\mathrm{P}<0.05)$. The variation of $\mathrm{pH}$ was very small and did not show any pattern that could suggest correlation with changes observed in the other studied variables, which is in agreement with results by CHENG and co-workers (2007) for guava juice and GómEZ-LóPEZ and co-workers (2010) for orange juice.

Table 2. pH evolution of non-sonicated and sonicated passion fruit juice during storage at two different temperatures

\begin{tabular}{lccc}
\hline Storage temperature $\left({ }^{\circ} \mathrm{C}\right)$ & Storage time (days) & Non-sonicated & Sonicated \\
\hline- & 0 & $3.04 \pm 0.00^{\mathrm{ef}}$ & $3.05 \pm 0.00^{\mathrm{de}}$ \\
4 & 2 & $3.06 \pm 0.01^{\mathrm{bcde}}$ & $3.01 \pm 0.01^{\mathrm{gh}}$ \\
4 & $3.05 \pm 0.01^{\mathrm{de}}$ & $2.98 \pm 0.01^{\mathrm{i}}$ \\
6 & $3.06 \pm 0.01^{\mathrm{bcde}}$ & $3.06 \pm 0.00^{\mathrm{bcde}}$ \\
& 8 & $3.02 \pm 0.01^{\mathrm{gh}}$ & $3.00 \pm 0.01^{\mathrm{hi}}$ \\
& 10 & $3.02 \pm 0.01^{\mathrm{fg}}$ & $3.00 \pm 0.01^{\mathrm{gh}}$ \\
10 & 2 & $3.07 \pm 0.01^{\mathrm{bc}}$ & $3.07 \pm 0.00^{\mathrm{bcd}}$ \\
4 & $3.10 \pm 0.01^{\mathrm{a}}$ & $3.08 \pm 0.01^{\mathrm{b}}$ \\
& 6 & $3.05 \pm 0.01^{\mathrm{cde}}$ & $3.07 \pm 0.01^{\mathrm{bcde}}$ \\
& 8 & $3.07 \pm 0.01^{\mathrm{bcd}}$ & $3.00 \pm 0.02^{\mathrm{bcd}}$ \\
\hline
\end{tabular}

Values denoted by different letters differ statistically $(\mathrm{P}<0.05)$.

Acta Alimentaria 46, 2017 


\subsection{Ascorbic acid content}

Sonication caused a significant $(\mathrm{P}<0.05)$ reduction in ascorbic acid content of PFJ (Fig. 4). Although this result might look discouraging, TIWARI and co-workers (2009) have shown that the degradation of ascorbic acid due to sonication is less than in thermally treated juice. Ascorbic acid may be degraded during sonication either due to thermolysis and combustion during the very short high local temperature increase of the cavitation bubble or reaction with hydroxyl radicals (TIWARI et al., 2009). In spite of this reduction, the concentration of ascorbic acid of all samples reached the same value $(\mathrm{P}>0.05)$ from the second day of storage and declined further during storage with similar $(\mathrm{P}>0.05)$ concentrations.

\section{Conclusions}

Ultrasound $(20 \mathrm{kHz}, 263 \mathrm{~W}, 89.25 \mu \mathrm{m})$ applied to passion fruit was able to decrease its aerobic mesophilic and yeast counts. The kinetic study showed that Weibull and log-linear + shoulder models yielded the best data fit for the inactivation of both microbial groups. The inactivation was not immediate but preceded by a shoulder. Storage studies showed that PFJ sonicated for 8 minutes was microbiologically stable for 10 days at $4{ }^{\circ} \mathrm{C}$ but not at $10{ }^{\circ} \mathrm{C}$. Sonication made the juice lighter, greener, and yellower, but the change was small, and no considerable variations in colour and $\mathrm{pH}$ were observed during storage at $4{ }^{\circ} \mathrm{C}$. Even though ultrasound treatment caused an immediate decrease in ascorbic acid content, the final concentration of this compound was equal to that of the untreated samples after the second day of storage. The microbial stability of sonicated PFJ stored at $4{ }^{\circ} \mathrm{C}$ along with the subtle effects of this non-thermal technology on colour and ascorbic acid content during refrigerated storage allows concluding that sonication could be a suitable alternative for PFJ processing.

This research was supported by the FONACIT project G-2000001538.

\section{References}

AOAC (1990): Official Methods of Analysis of the Association of Official Analytical Chemists. Virginia, USA.

Bevilacqua, A., Speranza, B., Campaniello, D., Sinigaglia, M. \& Corbo, M.R. (2014): Inactivation of spoiling yeasts of fruit juices by pulsed ultrasound. Food Bioprocess Tech., 7, 2189-2197.

Berk, Z. (2016): Citrus fruit processing. Academic Press, London, UK, 330 pages.

Cheng, L.H., Soh, C.Y., Liew, S.C. \& THE, F.F. (2007): Effects of sonication and carbonation on guava juice quality. Food Chem., 104, 1396-1401.

Fernandes, A.G., Santos, G.M., Silva, D.S., Sousa, P.H.M., Maia, G.A. \& Silva, R.W. (2011): Chemical and physicochemical characteristics changes during passion fruit processing. Ciência Tecnol. Alime., Campinas, 31, 747-751.

FRESHFEL (2015): European Fresh Produce Association. Position paper: exotic fruit - a highlight at POS. Consumption and trends. Fruit Logistica, Berlin February 5, 2015. http://www.freshfel.org/docs/2015/ Position_Papers/FRESHFEL_Exotic_fruit_5.02.2015.pdf (Last accessed March 31, 2017).

Geeraerd, A.H., Valdramidis, V.P. \& Van Impe, J.F. (2005): GInaFIT, a freeware tool to assess non-log-linear microbial survivor curves. Int. J. Food Microbiol., 102, 95-105.

Gómez-López, V.M., Orsolani, L., Martínez-Yépez, A. \& Tapia, M.S. (2010): Microbiological and sensory quality of sonicated calcium-added orange juice. LWT-Food Sci. Technol., 43, 808-813. 
Guerrouj, K., Sánchez-Rubio, M., Taboada-Rodríguez, A., Cava-Roda, R.M. \& Marín-Iniesta, F. (2016): Sonication at mild temperatures enhances bioactive compounds and microbiological quality of orange juice. Food Bioprod. Process., 99, 20-28.

Mohideen, F.W., Solval, K.M., Li, J., Zhang, J., Chouljenko, A. \& Chotiko, A. (2015): Effect of continuous ultrasonication on microbial counts and physic-chemical properties of blueberry (Vaccinium corymbosum) juice. LWT - Food Sci. Technol., 60, 563-570.

Piyasena, P., Mohareb, E. \& Mckellar, R.C. (2003): Inactivation of microbes using ultrasound: A review. Int. J. Food Microbiol., 87, 207-216.

Sandi, D., Chaves, J.B.P., De Souza, A.C.G., Parreiras, J.F.M., Da Silva, M.T.C. \& Constant, P.B.L. (2004): Hunter color dimensions, sugar content and volatile compounds in pasteurized yellow passion fruit juice (Passiflora edulis var. flavicarpa) during storage. Braz. Arch. Biol. Techn., 47, 233-245.

Soares, M.V.L., Alvez, E.G., Silva, L.M.A., Novotny, E.H., Marques, K., Wurlitzer, N.D., Narain, N. \& de Brito, E.S. (2017): Tracking thermal degradation on passion fruit juice through Nuclear Magnetic Resonance and chemometrics. Food Chem., 219, 1-6.

Tiwari, B.K., O’Donnell, C.P., Muthukumarappan, K. \& Cullen, P.J. (2008a): Effect of ultrasound processing on the quality and nutritional properties of fruit juices. Stewart Postharvest Rev., 5, 1-6.

Timari, B.K., Muthukumarappan, K., O’Donnell, C.P. \& Cullen, P.J. (2008b): Colour degradation and quality parameters of sonicated orange juice using response surface methodology. LWT - Food Sci. Technol., 41, $1876-1883$.

Tiwari, B.K., O’Donnell, C.P., Muthukumarappan, K. \& Cullen, P.J. (2009): Ascorbic acid degradation kinetics of sonicated orange juice during storage and comparison with thermally pasteurized juice. LWT - Food Sci. Technol., 42, 700-704.

Uysal, C., Demirel, N.N. \& Özcan, G. (2015): Microbial inactivation and physicochemical properties of ultrasound processed pomegranate juice. J. Food Prot., 78, 531-539.

Valero, M., Recrosio, N., Saura, D., Muñoz, N., Martí, N. \& Lizama, V. (2007): Effects of ultrasonic treatments in orange juice processing. J. Food Eng., 80, 509-516.

ZeNKER, M., HeInZ, V. \& KNoRR, D. (2003): Application of ultrasound assisted thermal processing for preservation and quality retention of liquid foods. J. Food Protect., 66, 1642-1649. 